\title{
Prevalence Of Irritable Bowel Syndrome, Celiac Disease And Their Manifestations Among Muhimbili University Of Health And Allied Sciences Staff And Students: A Cross Sectional Study
}

Adam Miraj Gembe ( $\nabla$ dr.adamgembe@gmail.com )

Department of Internal Medicine, Muhimbili University of Health and allied Sciences, Dar-es-salaam Tanzania

Research article

Keywords: Irritable bowel syndrome, Celiac disease, prevalence and manifestations.

Posted Date: April 14th, 2020

DOI: https://doi.org/10.21203/rs.3.rs-19611/v1

License: (c) (1) This work is licensed under a Creative Commons Attribution 4.0 International License. Read Full License 


\section{Abstract}

Background: Global prevalence of irritable bowel syndrome is high among medical students and health care professionals with significant morbidity. Similarly, the prevalence of celiac disease in irritable bowel syndrome is higher than the general population. These conditions impair quality of life and contribute to social-economic burden. In Tanzania, little is known about irritable bowel syndrome and celiac disease among medical students and health care professionals.

Methods: A cross sectional study was conducted to MUHAS and Mloganzila Academic Medical Center (MAMC) staff and students who fulfilled the online shared Rome IV criteria of irritable bowel syndrome from August to November 2018. A structured questionnaire was used to collect socio-demographic data, anthropometric measurements and clinical manifestations. Blood samples for full blood picture, liver enzymes and Erythrocyte Sedimentation Rate were taken. Celiac disease was tested using anti-tissue transglutaminase antibody test. Qualitative and quantitative data were summarized using frequency distribution tables. Chi-square and fishers exact test were used to study comparison between groups. Logistic regression was used to study associations. Data was analyzed using SPSS version 20.0 and a P value of $\leq 0.05$ was considered significant.

Results: Out of 1,321 participants, 192 (14.5\%) had irritable bowel syndrome in which 77 (40.1\%) were males and 115 (59.9\%) were females. Among the 192 participants with irritable bowel syndrome, 3 (1.6\%) were positive for celiac disease, 2 (66.7\%) were females and 1 (33.3\%) was a male. Of the 3 patients with CD, 2 had elevated ALAT and 1 had anaemia. Age (AOR 2.53, 95\% C.I 1.57-4.09), sex (AOR 1.67, 95\% C.I 1.16-2.41), marital status (AOR 4.95 C.I 2.07-11.82), alcohol intake (AOR 2.47, 95\% C.I 1.16-5.23), year of study (AOR 8.49, 95\% C.I 5.71-12.64) and sleep duration (AOR 2.24, 95\% C.I 1.23-4.06) were found to be independently associated with IBS.

Conclusion: Prevalence of IBS and its associated factors in our study population was similar to findings from studies done elsewhere. Also, our study revealed a low prevalence of celiac disease among IBS participants.

\section{Background}

Celiac Disease is an enduring gluten sensitive autoimmune disease affecting the small intestine in genetically predisposed persons (1). Irritable bowel syndrome is a functional gastrointestinal disorder characterized by abdominal pain and altered bowel habits in the absence of a specific bowel pathology (2). CD shares several symptoms that are present in the Rome IV criterion used in the diagnosis of IBS (3). Typically CD presents with chronic diarrhea, weight loss and failure to thrive. Atypically CD presents with iron deficiency, bloating, constipation, chronic fatigue, unexplained elevations in serum aminotransferases, headache, abdominal pain, and osteoporosis (4-7). As a result, IBS-like symptoms may delay $\mathrm{CD}$ diagnosis as $\mathrm{CD}$ is considered less prevalent in many regions compared to IBS. 
Global prevalence of people affected with IBS is of public importance. Evidence has shown that, there is a high prevalence of this condition among medical students and health care professionals $(39,40,56)$. In addition, reports indicate that the prevalence of $C D$ among patients with IBS is higher compared to the general population $(3,35,36)$.

Despite a high prevalence of IBS among medical students and health care professionals worldwide, availability of cost-effective and sensitive rapid screening tools for $C D$, the prevalence of IBS and $C D$ among MUHAS staff and students remain unknown.

Considering scarcity of data on both IBS and CD in our settings, the results obtained from this study will provide information on prevalence, manifestations of IBS and CD among MUHAS staff and students using a cost-effective and less invasive serological test.

In addition, this study will provide information on the disease burden of IBS and CD among staff and students at MUHAS. Such information may increase awareness about IBS and CD which in turn will lead to early detection and management of patients with these two conditions.

The objectives of the study were as follows:

- To determine the prevalence of IBS among MUHAS staff and students.

- To describe the socio-demographic characteristics and manifestations of IBS among MUHAS staff and students.

- To describe the factors associated with IBS among MUHAS staff and students.

- To determine the prevalence of celiac disease among MUHAS staff and students with IBS.

- To describe the socio-demographic characteristics and manifestations of celiac disease among MUHAS staff and students with IBS.

\section{Methods}

\section{Study design}

This was a cross-sectional study conducted at MUHAS and Mloganzila Academic Medical Center (MAMC) at Mloganzila campus with a total population of 2,500.

MUHAS is composed of five schools; namely Medicine, Dentistry, Pharmacy, Nursing, and Public Health and Social Sciences, two institutes; Institute of Allied Health Sciences and Institute of Traditional Medicine and twelve directorates.

MAMC is composed of 11 departments; Department of Internal medicine, general surgery, obstetrics and gynecology, pediatrics, orthopedic surgery, emergency, radiology, pharmacy, ophthalmology, psychiatry, and ear/nose/throat. 
This setting was chosen as it has a population with wide genetic heterogeneity, a likely population that consumes gluten-containing grains and a population that has shown to have a high prevalence of IBS from literature review.

\section{Inclusion criteria}

age of 18 years and above, all who consented to participate in the study.

\section{Exclusion criteria}

none consenting persons and females who had dysmenorrhea and Rome IV symptoms.

The study was conducted from August to November 2018. The minimal sample size used was 192 people. A consecutive sampling technique was employed in which all MUHAS health care professional staff and students on their respective areas were recruited until the sample size was attained. Health care professional staffs were introduced to the study through morning departmental meetings on their respective stations while students were introduced to the study after lecture hours. Participants were then required to complete an online survey Google document that was shared in various social network groups of staff and students. A written consent was obtained from the study participants. The survey tool questions were based on ROME IV criteria for irritable bowel syndrome where study participants were required to fill their mobile phone number, respond to the 8 questions in the tool and complete the sociodemographics section.

Then, those who fulfilled the ROME IV criteria of IBS were contacted via mobile phone and completed a second part of the questionnaire as described in the data collection tool that composed of anthropometric measurements and laboratory characteristics (annex IV).

Thereafter, participants were classified into diarrhea predominant IBS (IBS-D) if they had loose, mushy or watery stools in the last 3 month (question 8) without hard or lumpy stools (question 7); constipation predominant (IBS-C), if they had lumpy or hard stools without loose, mushy or watery stools in the last 3 month; Mixed IBS (IBS-M) if they had both hard stools and loose, mushy or watery stool in the last 3 month; and un subtype IBS (IBS-U), if they had neither hard, lumpy nor loose, mush or watery stool in the last 3 month. .

A Celiac Quick test (BIOHIT CELIAC QUICK TEST LOT NO X46.83), an immune-chromatographic test designed for the qualitative detection of antibodies ( $\mathrm{lgA} / \mathrm{lgG} / \mathrm{lgM})$ against human tissue transglutaminase in whole blood sample, was used for screening of CD. Also Full blood picture (FBP), Liver transaminases and erythrocyte sedimentation rate (ESR) were measured in the study participants.

NEGATIVE: Only one BLUE band appears across the result window close to the "C" letter (Control line) of the test cassette. This band must always appear.

POSITIVE: In addition to the BLUE control band, a distinguishable PINK-RED band also appears across the result window close to the letter " $T$ " (Test line) of the test cassette. The intensity of the line depends 
on the concentration of antibodies in the sample.

If no BLUE band appeared in the control area, the test was INVALID and was repeated with a new test cassette. Any line or color that appeared after 10 minutes had no diagnostic value.

\subsection{Data analysis}

The data obtained from the questionnaires was entered into statistical package of social sciences (SPSS) version 20 for Windows for data analysis. Cross checking of filled questionnaires after data collection was done for quality control of data.

The qualitative variables such as: sex, cigarette smoking/alcohol, manifestations CD and IBS were summarized using frequency distribution tables.

Quantitative variables in the study include; ages, number of seropositive and seronegative, were summarized by frequency distribution. Mean and standard deviation were employed for age.

Comparison of categorical variables between groups was performed using chi-square tests or fishers exact test. Logistic regression was employed to study for associations. The level of significance used was $P=0.05$.

\subsection{Ethical Consideration}

Permission was sought from MUHAS administration and MUHAS research ethical committee. Informed consent (annex I) was obtained from all participants that a vein puncture will be done to obtain a blood sample that was to be used for this study only.

\section{Results}

A total of 1,321 MUHAS staff and students were screened of which 192 participants fulfilled the ROME IV criteria for IBS and were screened for CD. The mean age of study participants was 25

4.04 years where 698 (52.8\%) were females. Majority of study participants were single 1054 (79.8\%) and students 1161 (87.9\%). Ongoing students 982 (74.3\%) accounted for greater part of student participants, where the highest number of participants 812 (61.5\%) were from school of medicine. School of dentistry had least participants $28(2.1 \%)$. Sleep duration was less than 7 hours in most of the study participants $1046(79.2 \%)$ as described in Table 1 below. 
Table 1

The demographic, anthropometric, clinical and laboratory characteristics of study participants among MUHAS staff and students. $\mathrm{N}=1321$

\begin{tabular}{|c|c|c|}
\hline Characteristics & & $\mathbf{N}(\%)$ \\
\hline Age & $\begin{array}{l}\text { Mean age years } \\
\text { SD }\end{array}$ & $\begin{array}{l}25 \\
4.04\end{array}$ \\
\hline \multirow[t]{4}{*}{ Age groups } & $18-27$ & $992(75)$ \\
\hline & $28-37$ & $317(24)$ \\
\hline & $38-47$ & $10(0.8)$ \\
\hline & $48-57$ & $2(0.2)$ \\
\hline Sex & $\begin{array}{l}\text { Female } \\
\text { Male }\end{array}$ & $\begin{array}{l}698(52.8) \\
623(47.2)\end{array}$ \\
\hline Marital status & Single/divorced/widow/er Married/cohabiting & $\begin{array}{l}1054(79.8) \\
267(20.2)\end{array}$ \\
\hline Alcohol & Ever & $111(8.4)$ \\
\hline Smoking & Ever & $7(0.5)$ \\
\hline Occupation & $\begin{array}{l}\text { Student } \\
\text { Employee }\end{array}$ & $\begin{array}{l}1161(87.9) \\
160(12.1)\end{array}$ \\
\hline $\begin{array}{l}\text { School/Institute of students } \\
(\mathrm{N}=1161)\end{array}$ & $\begin{array}{l}\text { Medicine } \\
\text { Dentistry } \\
\text { Pharmacy } \\
\text { Nursing } \\
\text { Allied sciences } \\
\text { Public health }\end{array}$ & $\begin{array}{l}812(61.5) \\
28(2.1) \\
84(6.4) \\
95(7.2) \\
107(8.1) \\
35(2.6)\end{array}$ \\
\hline $\begin{array}{l}\text { Year of study } \\
(\mathrm{N}=1161)\end{array}$ & $\begin{array}{l}\text { Ongoing } \\
\text { Finalist }\end{array}$ & $\begin{array}{l}965(83.1) \\
196(16.9)\end{array}$ \\
\hline Hours of sleep & $\begin{array}{l}\text { 7hours } \\
>\text { 7hours }\end{array}$ & $\begin{array}{l}1046(79.2) \\
275(20.8)\end{array}$ \\
\hline \multicolumn{3}{|l|}{ Clinical manifestations } \\
\hline \multirow[t]{3}{*}{ Symptoms } & Abdominal pain & $356(26.9)$ \\
\hline & Constipation & $292(22.1)$ \\
\hline & Diarrhea & $130(9.8)$ \\
\hline
\end{tabular}

Continuous variables are presented as mean \pm standard deviation, while categorical variables are presented as proportions, $\mathrm{N}$ : number of participants, Height and weight were used to calculate body mass index (BMI = weight in $\mathrm{kg} /$ height in meters $^{2}$. HB; hemoglobin, $\mathrm{MCV}$; mean cell volume, $\mathrm{MCHC}$; mean cell hemoglobin concentration, ESR; erythrocyte sedimentation rate, ALAT Aspartate aminotransferase, ALAT; Alanine aminotransferase and BMl; body mass index. 
Mixed

None

\section{Laboratory characteristics $\mathrm{N}=192$}

\begin{tabular}{lll} 
HB & Grams/deciliter mean & 13.2 \\
MCV & FD & 1.1 \\
\hline MCHC & & 91.2 \\
ESR & Grams/deciliter & 5.5 \\
\hline ALAT & Millimeter/hour & 31.5 \\
& & 1.3 \\
ASAT & Units/liter & 4.71 \\
& & 1.6 \\
Anthropometric measurements & Units/liter & 22.9 \\
N = 192 & & 5.4 \\
Height (range) & & 23.9 \\
& Centimeters mean & 4.6 \\
Weight & SD & 162.11 \\
& Kilograms & 6.6 \\
BMI & & 61.32 \\
\hline
\end{tabular}

Continuous variables are presented as mean \pm standard deviation, while categorical variables are presented as proportions, $\mathrm{N}$ : number of participants, Height and weight were used to calculate body mass index (BMI = weight in $\mathrm{kg} /$ height in meters $^{2}$. HB; hemoglobin, MCV; mean cell volume, MCHC; mean cell hemoglobin concentration, ESR; erythrocyte sedimentation rate, ALAT Aspartate aminotransferase, ALAT; Alanine aminotransferase and BMl; body mass index.

Cigarette smoking and alcohol were uncommon among the study participants thus, $7(0.5 \%)$ and 111 $(8.4 \%)$ in that order.

An alteration of abdominal pain, constipation and diarrhea was the predominant clinical manifestation evident in 445 (33.7\%) participants while diarrhea alone was the presenting complaint in $130(9.8 \%)$ participants.

The mean HB, red blood cell indices, liver enzymes and ESR among IBS study participants were within normal limits. The mean BMI among IBS participants was $23 \pm 2.6 \mathrm{~kg} / \mathrm{m} 2$. 
The prevalence of IBS among MUHAS staff and students was $14.5 \%$ as shown in Table 2 below.

Table 2

The prevalence of IBS among MUHAS staff and students

$\mathrm{N}=192$

$\begin{array}{lll}\text { Irritable bowel syndrome } & \text { IBS (\%) } & 192(14.5) \\ & \text { No IBS (\%) } & 1129(85.5)\end{array}$

The prevalence of CD among MUHAS staff and students with IBS was 1.6\% as shown in Table 3 below.

Table 3

The prevalence of celiac disease among MUHAS

staff and students with IBS

Celiac rapid test Positive (\%) $3(1.6)$

Negative (\%) $189(98.4)$

The baseline characteristics in participants with IBS and those with no IBS were similar in terms of alcohol intake and abdominal pain as part of the symptomatology however; those below an age 25 years, females, nonsmokers and with sleep duration less than seven hours were significantly predominant between the two arms. Nevertheless, among students a great part of ongoing students had no IBS. Moreover, among students with IBS ongoing students had less IBS 85 (48.6\%) compared to the finalist 90 (51.4\%). Furthermore, diarrhea, constipation and abdominal pain alternating with diarrhea and constipation were significantly seen among IBS participants as shown in Table 4 below. 
Table 4

The socio-demographics characteristics and manifestations of IBS among MUHAS staff and students $\mathrm{N}=1321$

\begin{tabular}{|lllll|}
\hline Characteristics & \multicolumn{2}{c}{$\begin{array}{c}\text { No IBS } \\
\text { N=1129 (\%) }\end{array}$} & IBS \\
N=192 (\%) & \\
\hline Age & 25 & $671(59.5)$ & $108(74.5)$ & 0.001 \\
\hline Sex & Female & $583(51.6)$ & $115(59.9)$ & 0.034 \\
\hline Alcohol & Never & $1041(92.2)$ & $169(88)$ & 0.053 \\
\hline Smoking & Never & $1125(99.6)$ & $189(98.4)$ & 0.068 \\
\hline Hours of sleep & 7hours & $877(77.7)$ & $169(88)$ & 0.001 \\
\hline Study year & Ongoing & $880(89.2)$ & $85(48.6)$ & $<0.001$ \\
\hline N = 1161) & & & & \\
\hline Clinical manifestations & & & & \\
\hline Symptoms & Abdominal pain (\%) & $164(14.5)$ & $192(100)$ & 0.646 \\
\hline & Diarrhea (\%) & $86(7.6)$ & $44(22.9)$ & $<0.001$ \\
\hline & Constipation (\%) & $252(22.3)$ & $40(20.8)$ & $<0.001$ \\
\hline & $\begin{array}{l}\text { Mixed (\%) } \\
\text { None (\%) }\end{array}$ & $337(29.8)$ & $108(56.3)$ & $<0.001$ \\
\hline
\end{tabular}

A total of seven variables namely age, sex, alcohol, smoking, marital status, year of study and sleep duration were entered in the univariate logistic regression analysis model. Age less than 25 years, female sex, being single, sleep duration less than 7 hours and finalist students were found to increase the probability of IBS.

All variables were entered in multivariate logistic regression analysis. After adjusting for cigarette smoking, age below 25 years (AOR 2.53, 95\% C.I 1.57-4.09), female sex (AOR 1.67, 95\% C.I 1.16-2.41), single marital status (AOR 4.95 C.I 2.07-11.82), alcohol use (AOR 2.47, 95\% C.I 1.16-5.23), final year of study (AOR 8.49, 95\% C.I 5.71-12.64) and sleep duration of less than 7 hours (AOR 2.24, 95\% C.I 1.234.06) were found to be independently associated with IBS as shown in Table 4 below.

There were 3 celiac disease patients among MUHAS staff and students with IBS where $2(66.7 \%)$ were females and 1 (33.3) was a male. All CD patients were below age of 25 years, never smoked cigarrete or taken alcohol.

All patients with celiac disease had healthy weight. Bloating was common among CD patients. The predominant IBS subtype among the CD positive patients was diarrhea $2(66.7 \%)$. 
One CD patient had mild microcytic hypochromic anemia whilst elevated ALAT evident in 2 patients as shown Table 5.

\section{Table 5}

Factors associated with IBS among MUHAS staff and students before and after adjustment $\mathrm{N}=1321$

\begin{tabular}{|c|c|c|c|c|c|c|c|}
\hline Variable & & $\begin{array}{l}\mathrm{P} \text { - } \\
\text { value }\end{array}$ & $\begin{array}{l}\text { Crude } \\
\text { OR }\end{array}$ & 95\% C.I & $\begin{array}{l}\text { P- } \\
\text { value }\end{array}$ & $\begin{array}{l}\text { Adjusted } \\
\text { OR }\end{array}$ & 95\% C.I \\
\hline Age & $\leq 25$ years & 0.005 & 1.61 & $1.15-2.24$ & $\begin{array}{l}< \\
0.001\end{array}$ & 2.53 & $1.57-4.09$ \\
\hline Sex & Female & 0.04 & 1.40 & $1.03-1.91$ & $<0.01$ & 1.67 & $1.16-2.41$ \\
\hline Alcohol & Ever used & 0.06 & 1.61 & $0.99-2.62$ & 0.02 & 2.47 & $1.16-5.23$ \\
\hline Smoking & $\begin{array}{l}\text { Ever } \\
\text { smoked }\end{array}$ & 0.05 & 4.46 & $\begin{array}{l}0.99- \\
20.11\end{array}$ & 0.27 & 3.29 & $\begin{array}{l}0.39- \\
27.43\end{array}$ \\
\hline $\begin{array}{l}\text { Marital } \\
\text { status }\end{array}$ & Single & $\begin{array}{l}< \\
0.001\end{array}$ & 2.56 & $1.56-4.20$ & $\begin{array}{l}< \\
0.001\end{array}$ & 4.95 & $\begin{array}{l}2.07- \\
11.82\end{array}$ \\
\hline $\begin{array}{l}\text { Year of } \\
\text { study }\end{array}$ & Finalist & $\begin{array}{l}< \\
0.001\end{array}$ & 5.16 & $3.67-7.24$ & $\begin{array}{l}< \\
0.001\end{array}$ & 8.49 & $\begin{array}{l}5.71- \\
12.64\end{array}$ \\
\hline $\begin{array}{l}\text { Sleep } \\
\text { duration }\end{array}$ & $<7$ hours & 0.001 & 2.11 & $1.34-3.34$ & 0.01 & 2.24 & $1.23-4.06$ \\
\hline
\end{tabular}


Table 6

The socio-demographic characteristics and manifestations of celiac disease among MUHAS staff and students with IBS $\mathrm{N}=3$

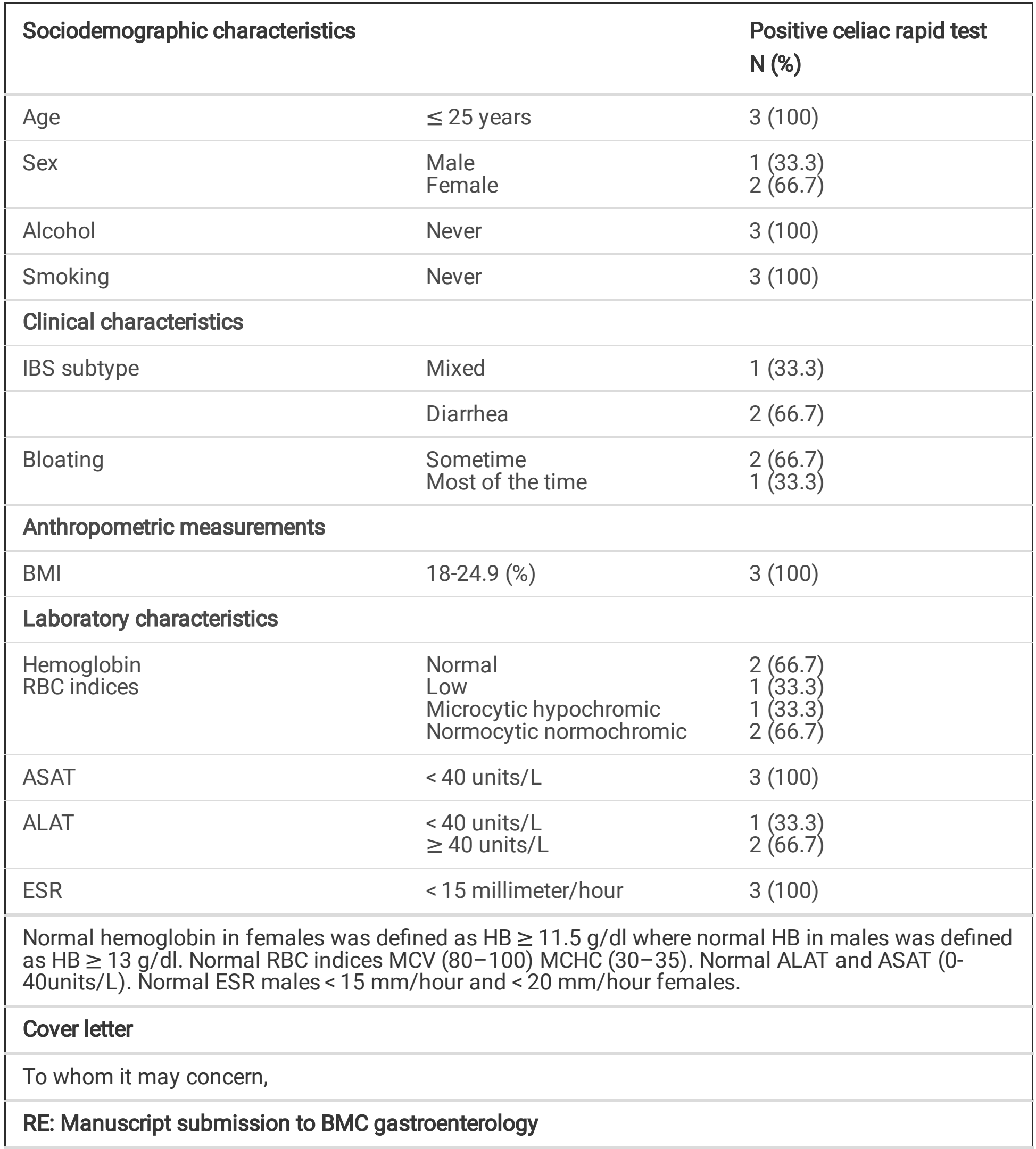


As caption above reads, I am writing to inform the journal that this work is original and has never been submitted to any other journal for publication. It is an agreement between the author and coauthor. The reason we think its valuable publishing the paper is no such kind information has been published from East Africa and as well as Sub Saharan Africa.

We hope this manuscript will be considered for publications.

Regards,

Dr. Adam Gembe.

Author.

\section{Discussion}

The global prevalence of IBS among medical students and health care professionals is high (8-10). The prevalence of IBS in this study was found to be $14.5 \%$. The finding is relatively consistency with findings among medical students in Saudi Arabia, Iran and health care professionals in Turkey where the prevalence of IBS was $13.7 \%, 12.6 \%$ and $13.5 \%$ respectively $(9,11,12)$. On the contrary, studies in Asia; Pakistan and China reported high prevalence of IBS among medical students $28.3 \%$ and $33.3 \%$ respectively whilst prevalence of $28.4 \%$ among health care professionals. Anxiety, stress and lack of sleep being the primary triggers $(9,13,14)$. In African medical students a relative comparable IBS prevalence to this study was evident in Nigeria and Sudan where the prevalence was $14.4 \%$ and $12.9 \%$ respectively (15). On the other hand, other studies among Nigerian medical student and nursing staff were consistency with some studies in Asia where the prevalence of IBS was as high as $26.1 \%$ and $45.2 \%$ in that order $(16,17)$.

The pathophysiology behind a high prevalence of IBS in medical students is constant nerve-racking environment to meet deadlines, examinations anxiety, long working and studying hours and less hours of sleep (8). Nevertheless, health care professionals are subjected to stressful environment due to the nature of the work and working environment (9). Although not fully defined, in genetically predisposed individual, stressful environment alter the micro biome-gut-brain axis that is key in IBS symptomatology. Stress, enhances the increase in systemic pro inflammatory cytokines and activates the hypothalamus pituitary adrenal axis. In turn, increases levels of corticotrophin releasing factor (CRF) from the hypothalamus that alter gut permeability causing infiltration of inflammatory cells, localized inflammation and mucosal edema. This results in changes in visceral neuromuscular function hence, IBS symptoms $(18,19)$.

IBS manifests in four major clinical subtypes as describe in literature review. Nevertheless, IBS shows a preponderance of females in their second and third decades of life. It was found that IBS-M subtype was common among MUHAS staff and students (56.3\%) largely affecting females (59.9\%). Similar findings have been reported in studies in Pakistan, Japan and China $(2,14,20)$. While in Iranian medical students 
IBS-C was the predominant subtype (81.6\%) (21).In African studies findings were similar to Pakistan, Japan and China where IBS-M was predominant $(19.6 \%$ and $60.7 \%)(15,17)$.

IBS has been shown to be associated with several factors as stipulated in literature review. In this study female gender, age below 25 years, alcohol intake and finalist students were independent predictors of IBS. In the same way, a study among medical students in China found that females were more affected than males (20). On the other hand, another study in China found that alcohol intake was significantly associated with symptoms of IBS (22). On the contrary, a study in Saudi Arabia among medical students IBS was predominant in males however, age and advanced academic levels were predictors of IBS (12). Studies in Turkey, Pakistan and Nigeria among health care professionals have displayed similar findings with studies among medical students in China where being a female was associated with $\operatorname{IBS}(9,10,17)$.

Evidence shows existence of CD among patients with IBS with variable burden across the globe. In this study, the prevalence of CD in patients with IBS based on the Rome IV criteria was $1.6 \%$. Similarly, studies from Asia and Europe relieved comparable CD prevalence among IBS patients $(23,24)$. On the contrary, studies from Middle East have shown a higher prevalence of up to $9.6 \%$ (25-27). Likewise, similar findings were seen in Mexico where the prevalence of CD in IBS patients was 5.21\% (28). Despite few studies in Africa, comparable findings to the middle East and North America were evident among Egyptian IBS patients where the prevalence of CD in IBS was found to be $8 \%$ (2). The low prevalence observed in study may be due to the fact that CD is uncommon in the Sub-Saharan Africa.

The manifestation of CD in IBS varies in different populations. In this study, CD was found in two patients with IBS-D subtype and one patient with IBS-M subtype. In the same way among Asians, CD has been seen commonly in patients with IBS-D subtype followed by IBD-M subtype and occasionally in IBS-C subtype $(27,29,30)$. Conversely, in Iranian patients CD was found to be prevalent in IBS- $U$ and less prevalent in the IBS-D subtype. A study in Africa has shown CD is common in IBS-D subtypes (24).

Furthermore, CD may present with bloating and weight loss, however, recent evidence has shown a decline in weight loss as a typical CD presentation (31). This study found that all CD patients had bloating and normal body mass index (BMI). In the same way, a study in India had similar findings where a normal mean BMI was evident in CD patients(23). Moreover, similar findings in terms of mean BMI were found in another study in Mexico (28). On the contrary, in Saudi Arabia it was found that patients with CD were underweight compared to those who were negative for $C D$ where as in Jordan, CD patients were overweight $(25,30)$.

Current evidence shows a preponderance of atypical CD manifestation such as iron deficiency anemia (IDA), asymptomatic elevated liver enzymes and ESR. In this study, two CD patients had elevated ALAT with normal ASAT as well as ESR. IDA was evident in 1 CD patient. Similarly, studies in India and Jordan, IDA was non-significantly evident in the CD patients $(23,30)$. Another study, in India, a non- significant difference in HB between CD patients versus non CD patients with IBS was found (32). In Africa, Egypt, a significant lower HB was evident in CD patients with IBS but non-significant difference in liver enzymes and ESR among the two arms (2). 
IDA in CD occurs as a result of loss of iron in the bowel enterocytes and mal-absorption of daily ingested iron (33). On the other hand, asymptomatic elevation in liver enzymes is due to increased intestinal permeability resulting in translocation of gut bacteria, kupffer cell stimulation, and production of tumor necrosis factor- $a$ (TNF-a), pro-inflammatory cytokine, and reactive oxygen species, resulting in nonalcoholic steatohepatitis (NASH). In addition to, CD share common immunogenic factors and immunopathogenesis with other hepatobiliary disorders such as autoimmune hepatitis, primary biliary cirrhosis and primary sclerosing Cholangitis that may contribute to asymptomatic elevation in liver enzymes (34).

\section{Study Limitations And Strength}

It was a single centered study confined to MUHAS and MUHAS teaching hospital therefore; the observed prevalence rates cannot be generalized. CD serologic test can be falsely negative in IgA deficiency, for which this study did not screen. Response bias as study participants were required to complete an online survey.

\section{Conclusions}

This study has revealed a high prevalence of IBS (14.5\%) comparable to other studies elsewhere.

Furthermore, the prevalence of CD among participants with IBS was low (1.6\%) in relation to studies done in other parts of the world. The commonest IBS subtype found was IBS-M subtype whereas most CD patients had IBS-D subtype. Age below 25 years, female gender, alcohol, and being finalist student were independent predictors of IBS. IDA was uncommon whilst elevated ALAT being common among CD patients.

\section{Abbreviations}

$\begin{array}{lll}\text { ALAT } & - & \text { Alanine aminotransferase } \\ \text { AOR } & - & \text { Adjusted odds ratio } \\ \text { ASAT } & - & \text { Aspartate aminotransferase } \\ \text { BMI } & - & \text { Body mass index } \\ \text { CD } & - & \text { Celiac disease } \\ \text { EMA } & - & \text { Endomysial antibody } \\ \text { ESR } & - & \text { Erythrocyte sedimentation rate } \\ \text { GFD } & - & \text { Gluten free diet }\end{array}$




$\begin{array}{lll}\text { HB } & - & \text { Haemoglobin } \\ \text { HLA } & - & \text { Human leukocyte antigen } \\ \text { IBS } & - & \text { Irritable bowel syndrome } \\ \text { IDA } & - & \text { Iron deficiency anemia } \\ \text { IFNY } & - & \text { Interferon gamma } \\ \text { IgA } & - & \text { Immunoglobulin A } \\ \text { IgG } & - & \text { Immunoglobulin G } \\ \text { IgM } & - & \text { Immunoglobulin M } \\ \text { Kg/m }{ }^{2} & - & \text { Kilogram/meter }{ }^{2} \\ \text { MAMC } & - & \text { Muhimbili Academic Medical Centre } \\ \text { MCV } & - & \text { Mean Cell Volume } \\ \text { MCHC } & - & \text { Mean Cell Hemoglobin Concentration } \\ \text { MUHAS } & - & \text { Muhimbili University of Health and Allied Sciences } \\ \text { OR } & - & \text { Odds ratio } \\ \text { PLT } & - & \text { Platelets } \\ \text { QoL } & - & \text { Quality of life } \\ \text { T1DM } & - & \text { Type 1 diabetes mellitus } \\ \text { WBC } & - & \text { White blood cells } \\ \text { ITGue transglutaminase }\end{array}$

\section{Declarations}

\section{Ethics approval and consent to participate}

The study was conducted after obtaining permission from the MUHAS institutional review board. Consent was sought from study participants.

\section{Consent for publication}


Not applicable.

\section{Availability of data and materials}

The data set supporting the conclusion of this article is available from the authors on request.

\section{Competing interests}

None.

\section{Funding}

This was a non-funded project.

\section{Author's contributions}

Dr. Gembe A had full access to all of the data in the study and takes responsibility for the integrity of the data and the accuracy of the data analysis.

\section{Acknowledgements}

I am obligated to express my sincere appreciation to Dr. Komba $\mathrm{E}$ for his advice and guidance at all stages of this research. I am appreciative also, to Prof. Pembe A, the vice Chancellor MUHAS for his permission to conduct this study.

I am thankful to the Almighty God for his protection and good health throughout the study period.

\section{References}

1. Gujral N. Celiac disease: Prevalence, diagnosis, pathogenesis and treatment. World J Gastroenterol [Internet]. 2012;18(42):6036.

2. Shalaby SA, Sayed MM, Ibrahim WA, Abdelhakam SM, Rushdy M. The prevalence of coeliac disease in patients fulfilling Rome III criteria for irritable bowel syndrome. Arab J Gastroenterol [Internet]. 2016;2016.

3. Sainsbury A, Sanders DS, Ford AC. Prevalence of irritable bowel syndrome-type symptoms in patients with celiac disease: A meta-analysis. Clin Gastroenterol Hepatol [Internet]. 2013;11(4):359-65.

4. Detlef Schuppan, MD P, Walburga Dieterich P. Pathogenesis, epidemiology, and clinical manifestations of celiac disease in adults - UpToDate [Internet]. 2017 [cited 2017 Oct 29].

5. Lebwohl B, Sanders DS, Green PHR. Coeliac disease. Lancet [Internet]. 2017;6736(17):1-12.

6. Mubarak A. Houwen RH. Wolters V. Celiac disease: an overview from pathophysiology to treatment. [Review]. Minerva Pediatr. 2012;(February).

7. Israeli E, Hershcovici T, Grotto I, Rouach Z, Branski D, Goldin E. Prevalence of celiac disease in an adult Jewish population in Israel. Isr Med Assoc J. 2010;12(5):266-9. 
8. Ibrahim NK. A systematic review of the prevalence and risk factors of irritable bowel syndrome among medical students. Turkish J Gastroenterol. 2016;2015(June 2015):10-6.

9. Tosun O, Dabak R, Sargin M, Dolapcioglu C, Ahishali E. Frequency of irritable bowel syndrome among healthcare personnel. Gastroenterol Nurs. 2016;39(3):227-31.

10. Sibyani MJ, Bardisi W, Ibrahim A. The Prevalence of Irritable Bowel Syndrome and its Associated Factors Among Physicians Working at Primary Health Care Centers of Ministry of Health in Jeddah , Saudi Arabia , 2017. 2018;2(12).

11. Fallah MS, Heidarzadeh A, Jafarshad R, Joukar F, Arami M, Keyhanian S, et al. Prevalence and Characteristics of Irritable Bowel Syndrome (IBS ) amongst Medical Students of Gilan Northern Province of Iran. Middle East J. 2009;1(2):100-5.

12. Almutairi M, Alqazlan M, Alshebromi A, Alawad M, Zafar M. Prevalence of Irritable Bowel Syndrome and its Associated Factors Among Medical Students. Int J Med Res Heal Sci [Internet]. 2017;6(2):110.

13. Naeem SS, Siddiqui EU, Kazi AN, Memon AA, Khan ST, Ahmed B. Prevalence and factors associated with irritable bowel syndrome among medical students of Karachi , Pakistan: A cross-sectional study. BMC Gastroenterol. 2012;5:255.

14. Liu Y, Liu L, Yang Y, He Y, Zhang Y, Wang M, et al. A School-Based Study of Irritable Bowel Syndrome in Medical Students in Beijing , China: Prevalence and Some Related Factors. Gastroenterol Res Pract. 2014;2014.

15. Jemilohun AC, Abayomi O, Adebayo PB. Prevalence of Irritable Bowel Syndrome, Psychological IIIHealth and Health-Seeking Behavior in a Population of Nigerian Medical Students. 2018;25(4):1-9.

16. Okeke EN, Agaba El, Gwamzhi L, Achinge Gl, Angbazo D, Malu AO. Prevalence of irritable bowel syndrome in a Nigerian student population. Afr J Med Med Sci [Internet]. 2005 Mar;34(1):33-36.

17. A. A, K.O. A. Association between irritable bowel syndrome and shift work: Prevalence and associated factors among nurses. J Gastroenterol Hepatol Res. 2014;3(11):1328-31.

18. Rodiño-Janeiro BK, Alonso-Cotoner C, Pigrau M, Lobo B, Vicario M, Santos J. Role of corticotropinreleasing factor in gastrointestinal permeability. J Neurogastroenterol Motil. 2015;21(1):33-50.

19. Holtmann GJ, Ford AC, Talley NJ. Pathophysiology of irritable bowel syndrome. Lancet Gastroenterol Hepatol. 2016;1(2):133-46.

20. Okami Y, Kato T, Nin G, Harada K, Aoi W, Wada S, et al. Lifestyle and psychological factors related to irritable bowel syndrome in nursing and medical school students. J Gastroenterol. 2011;46(12):1403-10.

21. SEmnani S, Abdolahi N, Roshandel G. IBS in iranian medical students.pdf. 2006. p. 974-8.

22. Hsu TY, He GY, Wang YC, Chen CY, Wang SH, Chen WK, et al. Alcohol use disorder increases the risk of irritable bowel disease: A nationwide retrospective cohort study. Med (United States). 2015;94(51):1-6. 
23. Pandav N, Bherwani S, Pandey V, Ingle M, Sawant P. A Prospective Unicentric Study of the Prevalence of Celiac Disease in Patients with Irritable Bowel Syndrome (IBS). Ann Int Med Dent Res. 2017;2(5):46-9.

24. Esin Korkut a, Mehmet Bektas a, Erkin Oztas b, Mevlut Kurt b, Hulya Cetinkaya a AO a. The prevalence of coeliac disease in patients fulfilling Rome III criteria for irritable bowel syndrome. Eur $\mathrm{J}$ Intern Med [Internet]. 2010;21(2):389-92.

25. Al-ajlan AS. Screening of coeliac disease in undetected adults and patients diagnosed with irritable bowel syndrome in Riyadh , Saudi Arabia. Saudi J Biol Sci [Internet]. 2016;23(4):462-6.

26. Cash BD, Rubenstein JH, Young PE, Gentry A, Nojkov B, Lee D, et al. The Prevalence of Celiac Disease Among Patients With Nonconstipated Irritable Bowel Syndrome Is Similar to Controls. World J Gastroenterol [Internet]. 2011;141(4):1187-93.

27. Bakhshipour A, Kazem S, Zakeri Z, Gharibi R, Bahari A, Ali M. Coeliac disease in irritable bowel syndrome (Rome III ) in Southeast Iran. Arab J Gastroenterol [Internet]. 2012;13(1):24-7.

28. Points K. Prevalence of celiac disease and related antibodies in patients diagnosed with irritable bowel syndrome according to the Rome III criteria . A case - control study. Neurogastroenterol Motil Neurogastroenterol. 2016;994-1000.

29. Wang H, Zhou G, Luo L, Crusius JBA, Yuan A, Kou J, et al. Serological screening for celiac disease in adult Chinese patients with diarrhea predominant irritable bowel syndrome. Medicine (Baltimore). 2015;94(42):e1779.

30. Jadallah KA, Khader YS. Celiac disease in patients with presumed irritable bowel syndrome: A casefinding study. World J Gastroenterol. 2009;15(42):5321-5.

31. Ludvigsson JF, Rubio-Tapia A, van Dyke CT, Melton LJ, Zinsmeister AR, Lahr BD, et al. Increasing Incidence of Celiac Disease in a North American Population. Am J Gastroenterol [Internet]. 2013;108(5):818-24.

32. Sharma H, Verma AK, Das P, Dattagupta S, Ahuja V. Original article Prevalence of celiac disease in Indian patients with irritable bowel syndrome and uninvestigated dyspepsia. World J Gastroenterol. 2015;

33. Baghbanian $\mathrm{m}$, farahat a, vahedian ha, sheyda e, zare-khormizi mr. the Prevalence of Celiac Disease in Patients With Iron-Deficiency Anemia in Center and South Area of Iran. Arq Gastroenterol [Internet]. 2015;52(4):278-82.

34. Prasad KK, Debi U, Sinha SK, Nain CK, Singh K. Hepatobiliary Disorders in Celiac Disease: An Update. Int J Hepatol [Internet]. 2011;2011(2009):1-7.

\section{Figures}




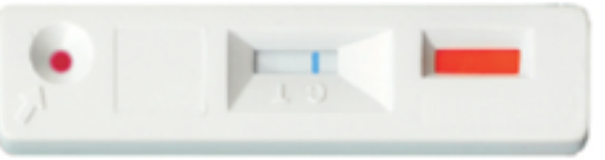

Figure 1

Negative CD test

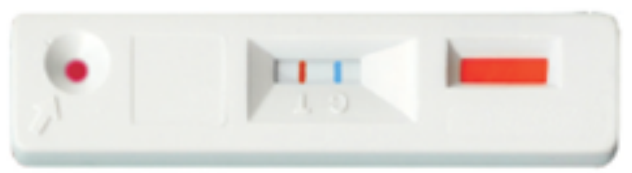

Figure 2

Positive CD test 